Article

\title{
A Stable Anti-Fouling Coating on PVDF Membrane Constructed of Polyphenol Tannic Acid, Polyethyleneimine and Metal Ion
}

\author{
Lili Wu, Qiuhu Lin, Cong Liu and Wanyu Chen * \\ School of Materials Science and Engineering, Wuhan University of Technology, Wuhan 430070, China; \\ polym_wl@whut.edu.cn (L.W.); 15551719435@163.com (Q.L.); lc_ibelic@163.com (C.L.) \\ * Correspondence: chenwanyu@whut.edu.cn
}

Received: 29 October 2019; Accepted: 19 November 2019; Published: 1 December 2019

\begin{abstract}
A hydrophilic and anti-fouling coating layer was constructed on a polyvinylidene fluoride (PVDF) microfiltration membrane by a novel surface modification method. The pristine membrane was firstly coated by (3-chloropropyl) trimethoxysilane/polyethyleneimine and tannic acid. Then, the metal ion was induced on the coating layer to coordinate with tannic acid and polyethyleneimine, forming a more stable and hydrophilic coating on the surface. The membrane's surface morphology and chemical element analysis showed that the Tannic acid/ polyethyleneimine (TA/PEI) coating layer was denser and had more stability after the addition of metal ions, and this may be due to the coordination bond formed between the TA/PEI coating and metal ions. The results of the water contact angle and pure water flux measurements showed that the hydrophilicity and wettability of the modified membranes were improved obviously after introducing the metal ion layers. The anti-fouling performance and stability of the modified membrane were also characterized by the underwater oil contact angle (OCA), the separation efficiency, and the contact angle variation value for before and after the rinsing experiment. The modified membrane showed obvious stability and antifouling. Moreover, the retention rate of some composite membranes could reach $99.6 \%$.
\end{abstract}

Keywords: surface modification; metal ion; anti-fouling; retention rate

\section{Introduction}

Water resources have been overexploited and severely polluted in recent decades due to the population explosion, chemical pollutant emissions, and low reuse rate of domestic sewage [1]. To protect the water on our planet, an efficient and generally accepted strategy is urgently needed for all organizations involved because water resources, such as freshwater lakes, underground rivers, and wetlands, are decreasing [2]. With the persistent research of scientists, membrane science and technology play an increasingly important role in the water treatment fields, which are seawater desalination, ion absorption from water, oil and protein resistance, and gas purification [3]. However, some hydrophobic membranes, which are polluted easily and have short life, cannot address those problems of the purification of domestic sewage, industrial wastewater, and biochemical pollution. Many methods have been developed, for example physical blending [4-6], polymeric and surface chemical grating $[7,8]$, surface chemical treatment $[9,10]$, and surface coating [11-15]. Compared with those other methods, surface coating has characteristics such as high efficiency, simple operation, and relatively low cost. The progress of surface modification was accelerated since mussel inspired surface chemistry was studied by Lee et al. in 2007 [16]. Polydopamine has two important characteristics, high catechol (3,4-dihydroxybenzene) content and high primary and secondary amine content [17]. Spontaneous deposition of a polydopamine coating occurs during the formation of polydopamine, and 
this primary coating can be used directly or used as a "primer" for immobilization of the secondary coating. The secondary coating is highly tailorable in composition and properties, so giving rise to the immense versatility and wide applications enjoyed by polydopamine coatings [18]. Many research works have been done on surface modification via the physical chemistry process of dopamine [19-25], but dopamine is so expensive and difficult to produce for industry that the research work might not transform into applications for water treatment. In order to solve this problem, tannic acid, which has a similar molecular structure as dopamine, is being studied by more and more scientists in recent years and is considered a potential material for surface modification applications.

Tannic acid has hydrophilicity and can be oxidized under weak alkaline conditions to carry out self-polymerization. During this process, many free radicals would form and react with that of the substrates by covalent and noncovalent bonds. Tannic acid is a hydrogen bond donator, as well as acceptor for producing hydrogen with various substrates [26]. Polyethyleneimine is a highly basic and positively charged aliphatic polymer, containing primary, secondary, and tertiary amino groups in a 1:2:1 ratio. Therefore, every third atom of the polymeric backbone is an amino nitrogen that may undergo protonation $[27,28]$. Tannic acid can form a crosslinking network with polyethyleneimine (PEI) via Michael addition or Schiff base reaction [29], hence strengthening the force between the crosslinking network and the substrates. At the same time, the addition of polyethyleneimine can facilitate the deposition of PEI, which provides an amine group to react with tannic acid [30], forming hydrophilic coating layers on the surface of membranes and reducing the deposition time and membrane pore blockage [19]. In addition, tannic acid and PEI can both react with metal ions by coordination to construct a three-dimensional crosslinking network, which is stable and has anti-fouling properties [31-34].

In order to improve the stability between the membrane surface and polyethyleneimine, a chemical substance needs to be introduced. The silane coupling agent hydrolyzes to generate silanol groups, then forms oligosiloxane by dehydration and condensation after contact with moisture in the air, which is favorable to enhance the crosslinking. Some silane coupling agents possess functional groups that can react with PEI, thus promoting its crosslinking [35-37]. Yang et al. used the amine derivatives to react with p-xylylene dichloride (XDC) via quaternization [38]; therefore, PEI can react with (3-chloropropyl) trimethoxysilane (CTS) using the same chemical mechanism. CTS has a similar structure to the silane coupling agent, so it can crosslink with PEI to form a stable network.

In this study, a stable and anti-fouling polyvinylidene fluoride (PVDF) microfiltration membrane was fabricated by surface coating, using tannic acid (TA), PEI, and metal ions as hydrophilic modifiers. Firstly, the pristine PVDF microfiltration membranes were coated by PEI/CTS coating, then decorated by TA. After that, the membranes were further modified by metal ions $\left(\mathrm{Zr}^{4+}, \mathrm{Fe}^{3+}, \mathrm{Al}^{3+}, \mathrm{Cu}^{2+}, \mathrm{Zn}^{2+}\right.$, or $\mathrm{Mn}^{2+}$ ) to obtain the final modified PVDF microfiltration membranes that were hydrophilic, stable, and resistant to oil. Moreover, the influence of the modification time of every metal ion on the modified membrane's properties was studied.

\section{Materials and Methods}

\subsection{Materials}

Tannic acid (TA), polyethyleneimine (PEI, $M_{\mathrm{w}}=600 \mathrm{Da}$ ), and (3-chloropropyl) trimethoxysilane (CTS) were purchased from Aladdin (Aladdin Industrial Corporation, Shanghai, China). $\mathrm{Zr}\left(\mathrm{SO}_{4}\right)_{2}$, $\mathrm{FeCl}_{3}, \mathrm{Al}_{2}\left(\mathrm{SO}_{4}\right)_{3} \cdot 18 \mathrm{H}_{2} \mathrm{O}, \mathrm{Cu}\left(\mathrm{NO}_{3}\right)_{2} \cdot 3 \mathrm{H}_{2} \mathrm{O}, \mathrm{Zn}\left(\mathrm{NO}_{3}\right)_{2} \cdot 6 \mathrm{H}_{2} \mathrm{O}$, and $\mathrm{MnSO}_{4}$ were bought from Sinopharm Chemical Reagent Co., Ltd. (Shanghai, China). The PVDF microfiltration membranes (MF, $0.22 \mu \mathrm{m}$ ) were obtained from Membrane Solutions (Nantong, China). Deionized water was prepared from a deionized water generator system (RX-108, XINRUI, Tengzhou xinrui analytical instrument Co. Ltd., Tengzhou, China). Isopropyl alcohol, tris(hydroxymethyl)aminomethane (Tris), hydrochloric acid $(\mathrm{HCl})$, toluene, Tween-80, and chloroform were purchased from Sinopharm Chemical Reagent Co., Ltd. 
(Shanghai, China). In this work, all chemical reagents were analytical grade unless specified otherwise, which were used without further purification.

\subsection{Preparation of TA/PEI/M Modified PVDF MF Membranes}

The preparation of TA/PEI modified PVDF MF membranes was reported in our previous work [39]. In brief, the pristine PVDF MF membranes were pretreated by isopropanol for $0.5 \mathrm{~h}$ and then immersed in deionized water for another $0.5 \mathrm{~h}$ to clear their pores. After that, the pretreated membranes were soaked in the PEI/CTS solution, which was prepared by $20 \mathrm{mg}$ PEI, $20 \mathrm{mg}$ CTS, and $100 \mathrm{~mL}$ deionized water for $10 \mathrm{~h}$ at $25^{\circ} \mathrm{C}$. Next, the membranes were washed with deionized water several times and immersed in $100 \mathrm{~mL}$ Tris- $\mathrm{HCl}$ buffer $(\mathrm{pH}=7.8)$ that contained $20 \mathrm{mg}$ TA for $12 \mathrm{~h}$ at $25^{\circ} \mathrm{C}$. Finally, the membranes were immersed in $100 \mathrm{~mL} 0.2 \mathrm{~g} / \mathrm{L}$ metal ion solution for a certain time ( $1 \mathrm{~min}, 3 \mathrm{~min}$, $5 \mathrm{~min}, 10 \mathrm{~min} 15 \mathrm{~min}$, or $30 \mathrm{~min}$ ) at $25^{\circ} \mathrm{C}$, obtaining the tannic acid, polyethyleneimine and mental ions (TA/PEI/M) composite modified PVDF MF membranes ( $\mathrm{x}-\mathrm{mM}$, where " $\mathrm{x}$ " is the soaking time, " $\mathrm{m}$ " means the membrane, and " $\mathrm{M}$ " is the metal ion). The modification process is shown in Figure 1.

(a)

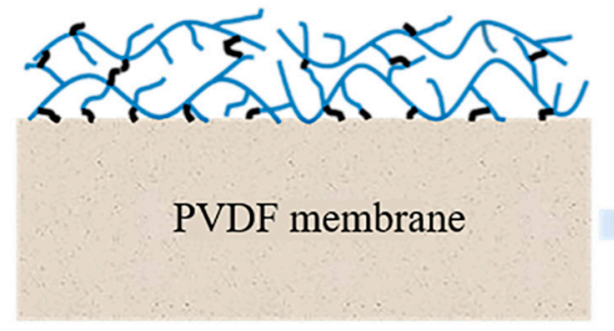

(c)

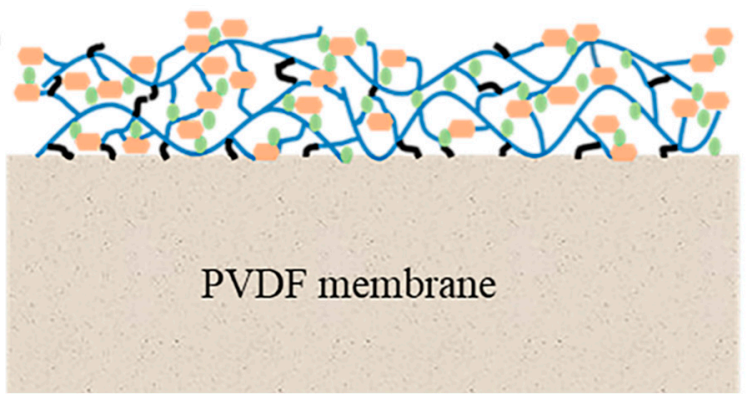

(b)

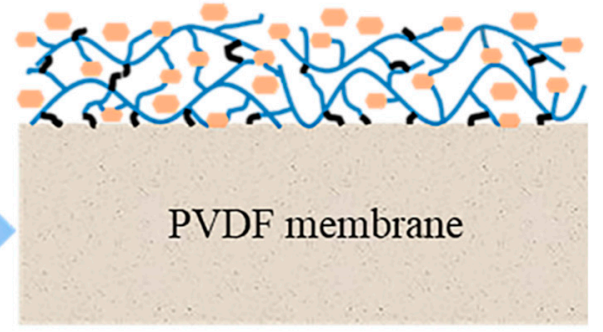

Figure 1. The modification process of the PVDF membrane: (a) the membrane coated with PEI/(3-chloropropyl) trimethoxysilane (CTS); (b) the membrane coated with PEI/CTS-TA; (c) the membrane coated with PEI/CTS-tannic acid (TA)-M (metal ion).

\subsection{Physicochemical Properties of Modified PVDF MF Membranes}

The surface chemical elements of the modified PVDF MF membranes were characterized by X-ray photoelectron spectroscopy (XPS, ESCALAB250Xi, Thermo-Fisher, Waltham, MA, USA), which used $\mathrm{Al}-\mathrm{K} \alpha$ as the radiation source. The membrane surface morphology was observed by field-emission scanning electron microscope (FESEM, Zeiss Ultra Plus, Zeiss, Germany) with an accelerating voltage of $5.0 \mathrm{kV}$.

\subsection{Hydrophilicity and Oleophobicity of Modified PVDF MF Membranes}

The hydrophilicity of the membranes was characterized by the water contact angle (WCA) and pure water flux (WF). The oleophobicity of uncoated and coated membranes was characterized by the underwater oil contact angle (OCA) and flux recovery ratio (FRR). The WCA and OCA were measured by a contact angle test system (JC2000C, Zhongchen, Shanghai zhongchen digital technology equipment Co. Ltd., Shnaghai, China). In addition, the emulsion flux of the membranes was also tested to study the membrane separation ability. The emulsion was made by mixing toluene and water $(1: 99, v / v)$ 
with the addition of $0.02 \mathrm{mg}$ Tween-80 per milliliter of emulsion under a high stirring speed for at least $4 \mathrm{~h}$. The emulsion flux and water flux were done by a vacuum filter system (JINTENG, Tianjin jinteng technology Co. Ltd., Tianjin, China) at a stable pressure $(0.1 \mathrm{MPa})$ and at room temperature, and the average value of three measurements of every sample was taken. Moreover, the rejection for the emulsion was characterized by the UV-visible absorption spectrum (UV-Vis). The flux (F), FRR, and emulsion rejection ratio $\left(R_{\mathrm{j}}\right)$ were calculated using Equations (1)-(3), respectively:

$$
\begin{gathered}
\mathrm{F}=\frac{V}{A \Delta t} \\
\mathrm{FRR}=\frac{F_{w_{2}}}{F_{w_{1}}} \times 100 \% \\
R_{j}=\left(1-\frac{C_{P}}{C_{0}}\right) \times 100 \%
\end{gathered}
$$

where $V, A$, and $\Delta t$ represent the permeate volume (L), the effective membrane area $\left(\mathrm{m}^{2}\right)$, and the filtration time (h), respectively. $F \mathrm{w}_{1}$ and $F \mathrm{w}_{2}$ represent the pure water flux before and after the emulsion filtration, respectively. $C_{\mathrm{p}}$ and $C_{0}$ represent the concentration of the permeate solution and original solution, respectively. The concentration was measured by a UV-Vis spectrophotometer at $261 \mathrm{~nm}$ for toluene.

\subsection{Hydrophilic Stability of Modified PVDF MF Membranes}

The hydrophilic stability of the membranes was measured by the long term rinsing experiment in pure water for seven days, namely the membranes were fixed to the wall of a beaker with a magnetic stirrer, then rinsed by the flow of water. The WCA and pure water flux of the pristine and modified membranes before and after the rinsing experiment were tested. Moreover, the contact angle variation value $\left(\Delta_{C A}\right)$ and contact angle recovery ratio $(C R)$ were used firstly to study the stability of the membranes, which were calculated by Equations (4) and (5):

$$
\begin{gathered}
\Delta_{C A}=C A_{0}-C A_{1} \\
\mathrm{CR}=\frac{C A_{1}-C A_{2}}{C A_{1}-C A_{0}}
\end{gathered}
$$

where $\mathrm{CA}_{0}, \mathrm{CA}_{1}$, and $\mathrm{CA}_{2}$ represent the contact angle of the modified membrane, the membrane after the pure water flux test, and the recovery membrane, which was soaked in the pure water for $72 \mathrm{~h}$ after the pure water flux test.

\section{Results and Discussion}

\subsection{Surface Characterization of the Chemical Elements}

Figure 2 shows the XPS spectra of the TA/PEI/M modified PVDF MF membranes. There were obvious new signals, which represented the $\mathrm{Zr} 3 \mathrm{~d}, \mathrm{Fe} 2 \mathrm{p}$, and $\mathrm{Cu} 2 \mathrm{p}$ peak in the spectra of the $3-\mathrm{mZr}^{4+}, 5-\mathrm{mFe}^{3+}$, and $10-\mathrm{mCu}^{2+}$ membranes, respectively. Moreover, the $\mathrm{O}$ and $\mathrm{N}$ signal could also be observed, indicating that TA and PEI were coated on the membrane surface successfully. The chemical composition of the modified membranes is shown in Table 1 . The $\mathrm{O} / \mathrm{N}$ ratios of the modified membranes were different. The $\mathrm{O} / \mathrm{N}$ ratio of $3-\mathrm{mZr}^{4+}$ and $10-\mathrm{mCu}^{2+}$ was relatively large, which was due to the addition of acid ions such as $\mathrm{SO}_{4}{ }^{2-}$ from $\mathrm{Zr}\left(\mathrm{SO}_{4}\right)_{2}$ and $\mathrm{NO}_{3}{ }^{-}$from $\mathrm{Cu}\left(\mathrm{NO}_{3}\right)_{2}$; however, the use of $\mathrm{FeCl}_{3}$ did not provide acid ions, so that the $\mathrm{O} / \mathrm{N}$ ratio of the $5-\mathrm{mFe}^{3+}$ membrane was the minimum. 


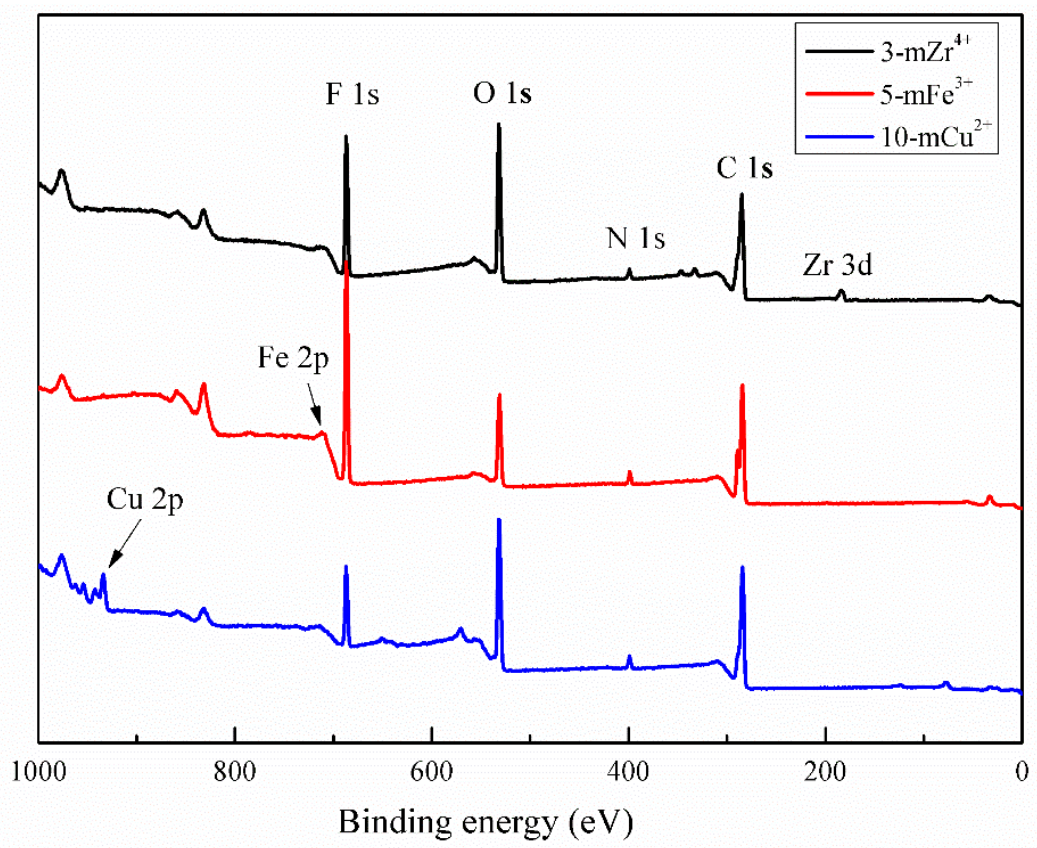

Figure 2. XPS spectra of the $3-\mathrm{mZr}^{4+}, 5-\mathrm{mFe}^{3+}$, and $10-\mathrm{mCu}^{2+}$ membrane.

Table 1. The chemical composition of the modified membranes.

\begin{tabular}{cccccccc}
\hline \multirow{2}{*}{ Modified Membranes } & \multicolumn{9}{c}{ Composition (at.\%) } & \multicolumn{2}{c}{. } & O & $\mathbf{N}$ & $\mathbf{Z r}$ & Fe & O/N \\
\hline $3-\mathrm{mZr}^{4+}$ & 68.11 & 28.19 & 3.04 & 0.65 & 0 & 0 & 9.27 \\
$5-\mathrm{mFe}^{3+}$ & 75.78 & 18.37 & 3.42 & 0 & 2.43 & 0 & 5.37 \\
$10-\mathrm{mCu}^{2+}$ & 66.06 & 27.61 & 3.68 & 0 & 0 & 2.53 & 7.50 \\
\hline
\end{tabular}

\subsection{Surface Morphologies of the TA/PEI/M Modified Membranes}

The surface morphologies of pristine and modified PVDF MF membranes are given in Figure S1 (from the supplementary materials) and Figure 3, respectively. Compared with the pristine membrane, which possessed many bumps on the surface, the TA/PEI modified membrane was obviously coated by the coating layers formed by TA and PEI to cover the bumps or around them, after the addition of metal ions, the coating layers were connected to each other and more obvious around the bumps, such as the coating layers of the $3-\mathrm{mZr}^{4+}, 5-\mathrm{mFe}^{3+}$, and $3 \mathrm{~m}-\mathrm{Zn}^{2+}$ membranes. The coating layer area on the surface of the $3-\mathrm{mAl}^{3+}, 10-\mathrm{mCu}^{2+}$, and $3-\mathrm{mMn}^{2+}$ membranes was thicker, which could be explained by two facts. First, the $\mathrm{Cu}^{2+}$ with strong oxidizing ability could further improve the oxidation degree of TA. Secondly, the structure of the layers was changed by the metal ions, which could coordinate with TA and PEI, increasing their crosslinking and making the coating layers more compact [40]. These results indicate that the introduction of a hydrophilic modifier (TA/PEI or TA/PEI/M) could influence the morphology of the membranes. 

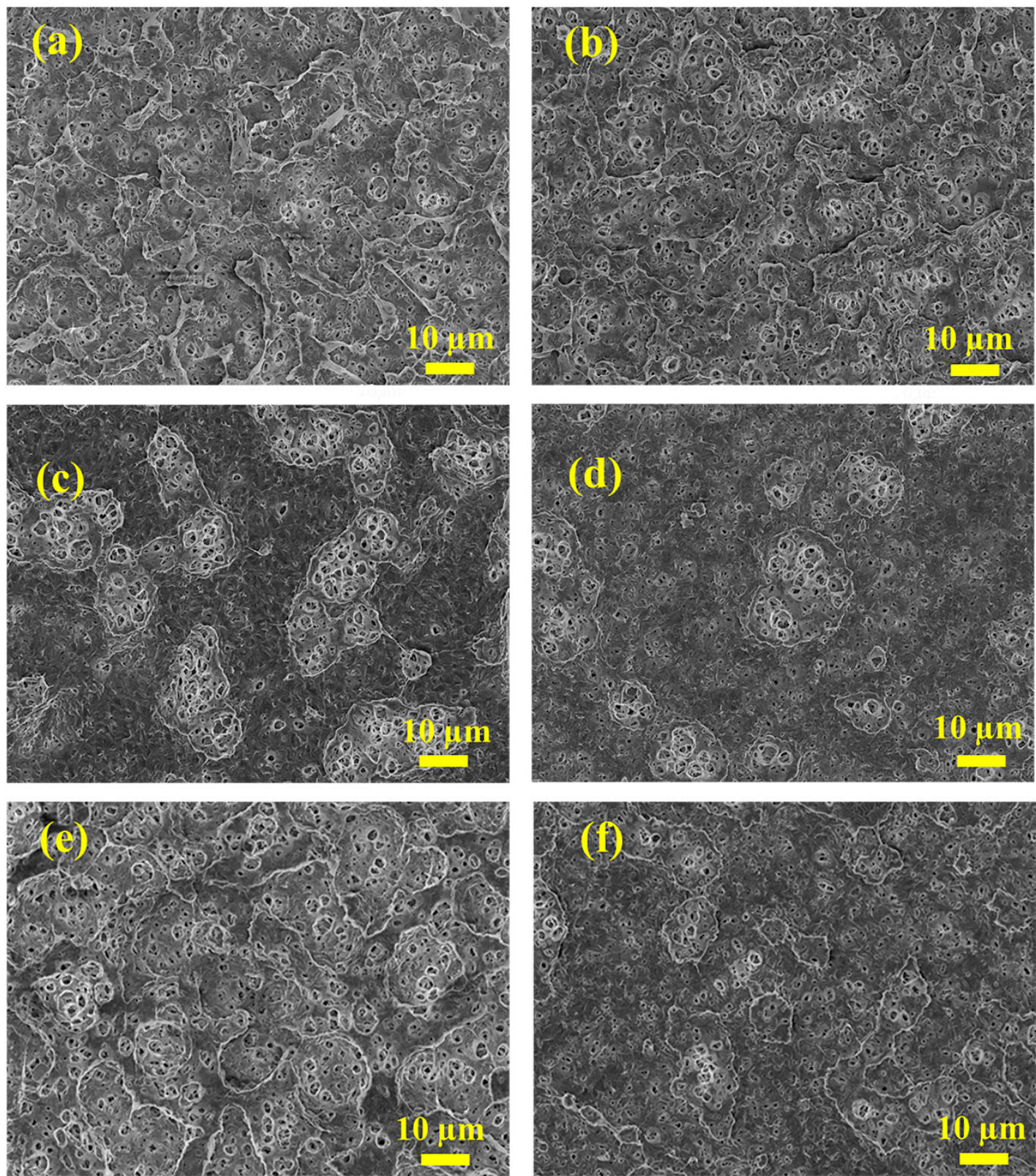

Figure 3. FESEM images of TA/PEI/M modified PVDF microfiltration (MF) membranes. (a,b,c,d,e,f) The 3- $\mathrm{mZr}^{4+}, 5-\mathrm{mFe}^{3+}, 3-\mathrm{mAl}^{3+}, 10-\mathrm{mCu}^{2+}, 3-\mathrm{mZn}^{2+}$, and 3- $\mathrm{mMn}^{2+}$ membranes, respectively.

\subsection{Hydrophilicity of the TA/PEI/M Modified Membranes}

The influence of the modification time of metal ions on the hydrophilicity of the modified membranes is shown in Figures S2-S13 (from the supplementary materials). The hydrophilicity of TA/PEI/M modified PVDF MF membranes improved greatly, and the largest pure water flux was $13,028 \mathrm{~L} / \mathrm{m}^{2} \cdot \mathrm{h}\left(10-\mathrm{mCu}^{2+}\right)$, while the smallest water contact angle was $19^{\circ}\left(3 \mathrm{~m}-\mathrm{Al}^{3+}\right)$. On the one hand, as the metal ions had different oxidation states, forming different hydrophilic coating layers that had various structures, especially the metal ions with a higher oxidation state could induce the polymerization of TA, increasing its crosslinking with PEI on the surface of the membranes. On the other hand, the element content of the modified membrane surface may also influence the hydrophilicity of the membranes, as seen by the XPS and contact angle analysis. The contact angle images of modified membranes are given in Figures 4 and 5. Compared with the pristine membrane, the WCA of TA/PEI/M modified membranes decreased obviously, and the OCA of the modified membranes was larger than $157^{\circ}$; the OCA of the pristine PVDF MF membrane was only $140^{\circ}$, and all the results demonstrated that 
the hydrophilicity and oleophobicity of the TA/PEI/M modified membranes were enhanced. Owning to the coating of the hydrophilic layers formed, the surface roughness of the TA/PEI/M modified membrane increased obviously. With the change of the membrane surface roughness, the surface capillary action and solid-liquid-gas three-phase balance of the membrane would be directly impacted. According to the mechanism of surface roughness, the rougher the surface is, the more hydrophilic the surface. As a result, the surface roughness of the modified membranes increased, leading to the membrane surface being more hydrophilic and oleophobic.

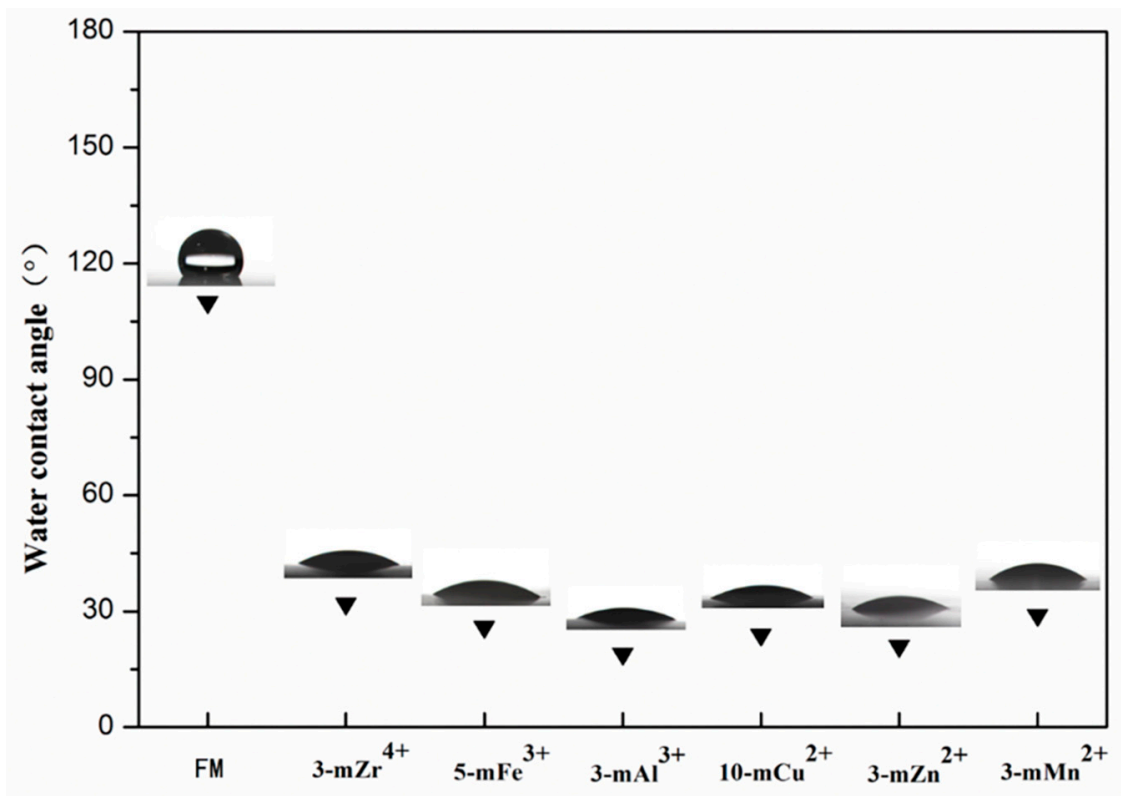

Figure 4. The WCA of the pristine PVDF membrane (FM) and TA/PEI/M modified PVDF MF membranes.

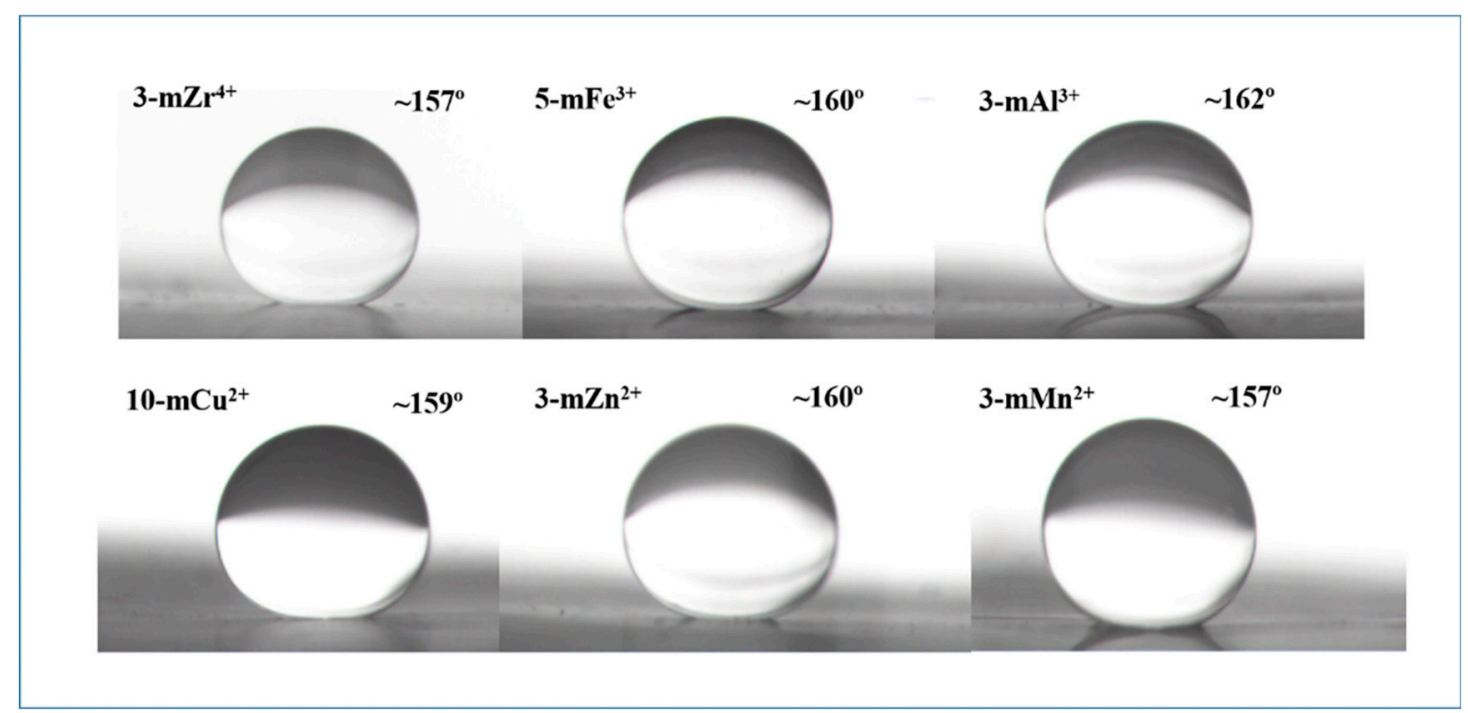

Figure 5. The oil contact angle (OCA) of the TA/PEI/M modified PVDF MF membranes.

\subsection{Anti-Fouling Performance of TA/PEI/M Modified Membranes}

The emulsion flux and flux recovery ratio of the modified membranes are shown in Figure 6. Because the metal ions with a higher oxidation state, such as $\mathrm{Zr}^{4+}, \mathrm{Fe}^{3+}$, and $\mathrm{Cu}^{2+}$, could induce the polymerization of TA to compact the coating layers, the pores of the membranes were covered by those hydrophilic coating layers, and it was difficult for the emulsion to pass through them. The FRR of the $3-\mathrm{mZr}^{4+}, 5-\mathrm{mFe}^{3+}$, and $10-\mathrm{mCu}^{2+}$ membranes was $92.7 \%, 89.7 \%$, and $91.7 \%$, respectively, and the FRR 
of the $3-\mathrm{mAl}^{3+}, 3-\mathrm{mZn}^{2+}$, and 3- $\mathrm{mMn}^{2+}$ membranes was $90.9 \%, 87.3 \%$, and $87.8 \%$, respectively. Because the surface roughness of the $3-\mathrm{mAl}^{3+}, 3-\mathrm{mZn}^{2+}$, and $3-\mathrm{mMn}^{2+}$ modified membranes was relatively greater by SEM analysis, which could increase the contaminated surface area, the FRR of the 3-mAl ${ }^{3+}$, $3-\mathrm{mZn}^{2+}$, and 3-mMn ${ }^{2+}$ membranes was relatively lower. The resistance of the $3-\mathrm{mZr}^{4+}, 5-\mathrm{mFe}^{3+}$, and $10-\mathrm{mCu}^{2+}$ membranes is given in Figures 7 and 8 ; the peak of toluene nearly disappeared, improving the outstanding anti-fouling performance of the modified membranes, and the emulsion rejection ratio resistance of all modified membranes for the toluene emulsion was approximately $99 \%$. The emulsion rejection of the 3-mZr $\mathrm{rr}^{4+}$ membrane was $99.6 \%$. This was due to $\mathrm{zr}^{4+}$ and $\mathrm{Fe}^{3+}$ being hard acids and $\mathrm{Cu}^{2+}$ being a junction acid, while the primary amine and secondary amines in polyethyleneimine are hard bases. According to the Pearson hard-soft-acid-base (HSAB) theory, those metal ions can coordinate with PEI and TA to form a complex crosslinking network on the surface of the pristine PVDF membranes, effectively improve the emulsion rejection ratio of the modified membranes.

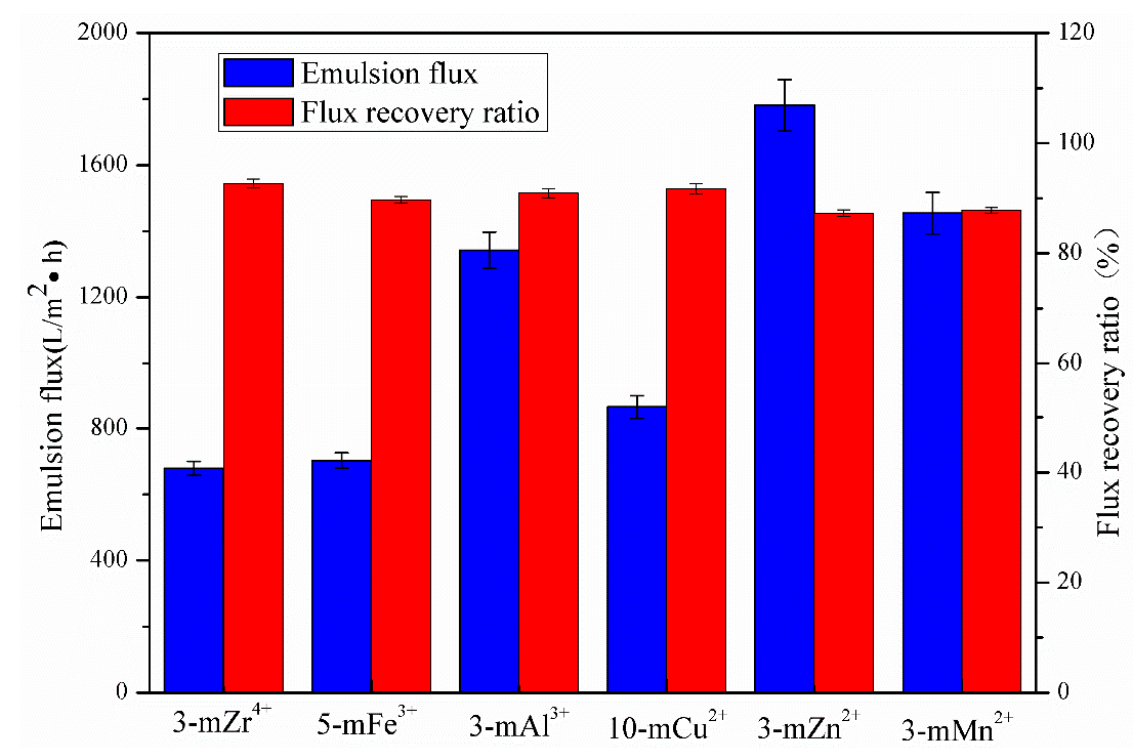

Figure 6. Emulsion flux and flux recovery ratio of TA/PEI/M modified membranes.

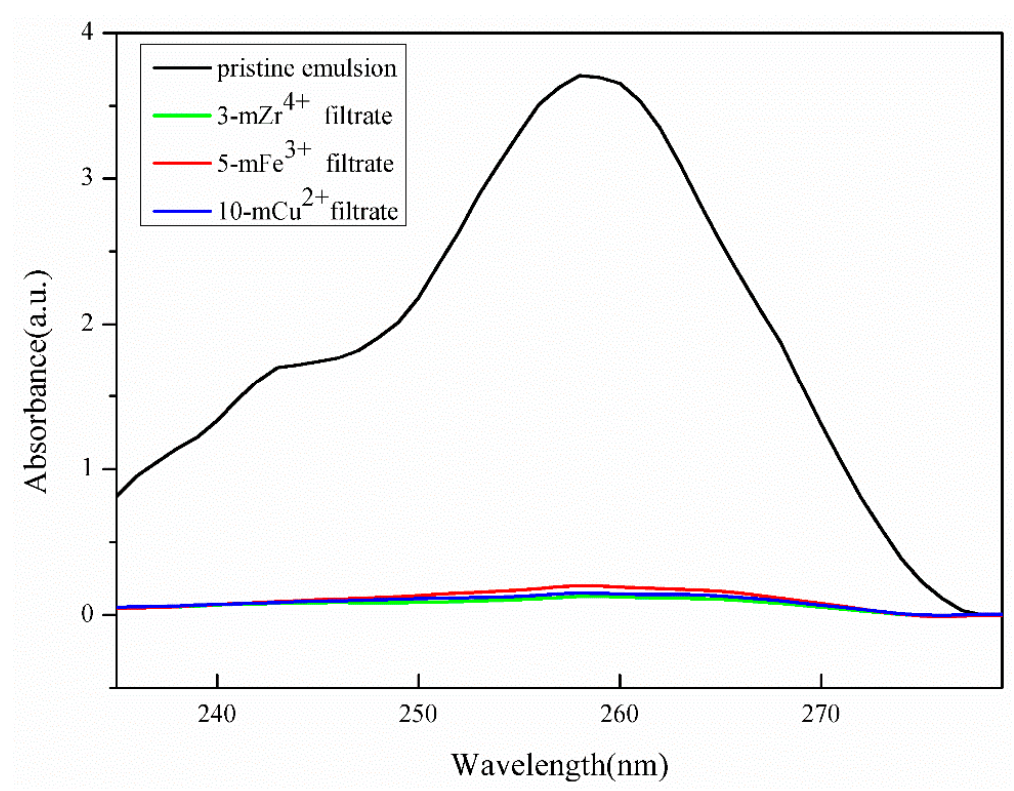

Figure 7. The UV-Vis spectrum of the pristine emulsion and the filtrate of $3-\mathrm{mZr}^{4+}, 5-\mathrm{mFe}^{3+}$, and $10-\mathrm{mCu}^{2+}$ membranes. 


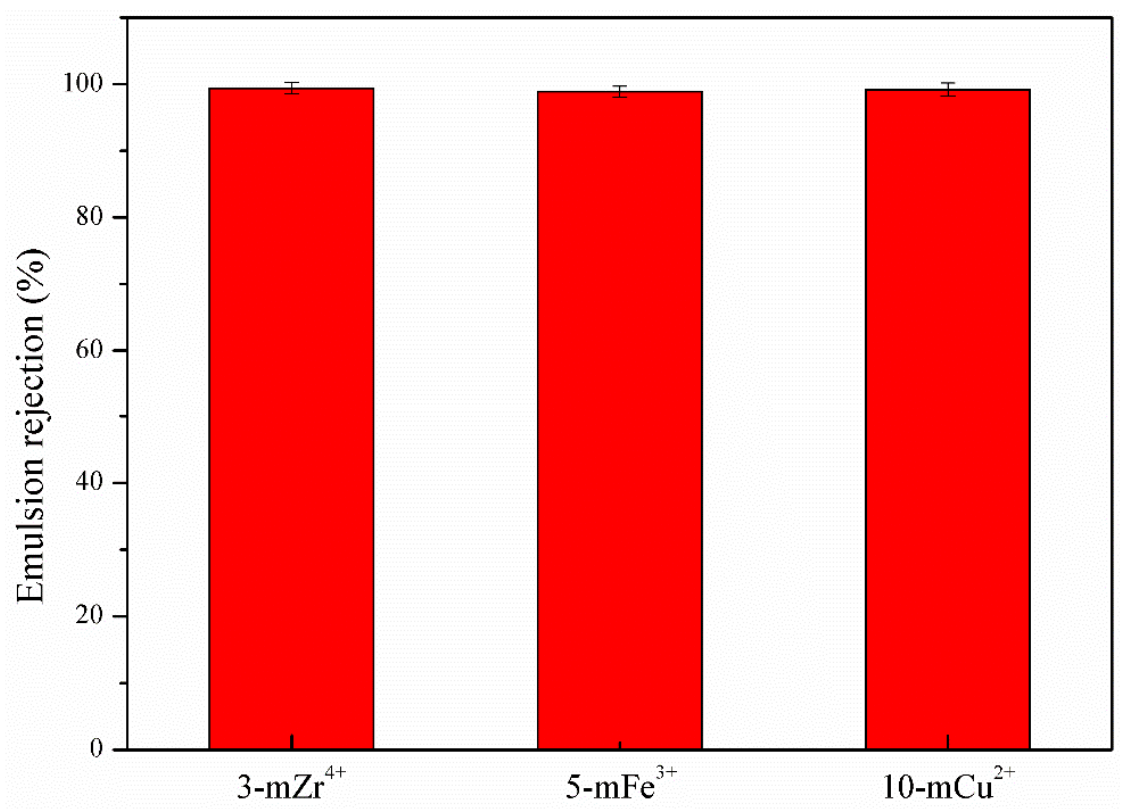

Figure 8. Emulsion rejection of $3-\mathrm{mZr}^{4+}, 5-\mathrm{mFe}^{3+}$, and $10-\mathrm{mCu}^{2+}$ membranes.

\subsection{Stability of TA/PEI/M Modified Membranes}

Figure 9 shows the pure WF of the TA/PEI and TA/PEI/M modified membranes. It can be seen that the 10-mCu ${ }^{2+}, 3-\mathrm{mZn}^{2+}$, and 3- $\mathrm{ZZr}^{4+}$ modified membranes had significant improvements compared with the TA/PEI modified membrane. This was due to $\mathrm{Cu}^{2+}, \mathrm{Zn}^{2+}$, and $\mathrm{Zr}^{4+}$ having a larger ionic radius $\left(74 \mathrm{pm}, 73 \mathrm{pm}\right.$, and $72 \mathrm{pm}$, respectively) compared with $\mathrm{Fe}^{3+}, \mathrm{Al}^{3+}$, and $\mathrm{Mn}^{+2}$ (50 pm, $55 \mathrm{pm}$, and $67 \mathrm{pm}$, respectively), resulting in their $\left(\mathrm{Cu}^{2+}, \mathrm{Zn}^{2+}\right.$, and $\left.\mathrm{Zr}^{4+}\right)$ ability to increase hydrophilicity, while effective reducing the clogging of the pores of the modified membranes. The pure water flux of the $5-\mathrm{mFe}^{3+}, 3-\mathrm{mAl}^{3+}$, and 3- $\mathrm{mMn}^{2+}$ modified membranes slightly decreased due to the blockage of the modified membranes' pores.



Figure 9. Pure water flux of the TA/PEI/M and TA/PEI modified membranes before and after the rinsing experiment and the pure water flux variation $\left(\Delta_{W}\right)$. 
The variation of pure WF and WCA is shown in Figures 9 and 10, respectively. The pure WF and WCA variation value of the TA/PEI/M modified PVDF MF membranes was obviously lower than the TA/PEI modified membranes, illustrating that the stability of the modified membranes was further strengthened after the addition of the metal ions, which could coordinate with both TA and PEI. The pure WF variation value of the $3-\mathrm{mMn}^{2+}$ membrane was the smallest, and the WCA variation value of the $10-\mathrm{mCu}^{2+}$ membrane was the lowest. As the electron orbits of the metal atoms were different, they had different ways of reacting with TA and PEI. In addition, due to different metal ions having unequal hydration energy, that is by metal cations combined with water releasing energy, this would directly impact the solubility of metal ions in aqueous solution. When the hydration energy increased, the solubility of the coating in aqueous solution and stability of the modified membrane were also enhanced. The coating layers of the TA/PEI/M modified PVDF MF membranes had different morphologies that were significant; therefore, the pure water flux variation $\left(\Delta_{W}\right), \Delta_{C A}$, and $C R$ of every TA/PEI/M modified membrane were different.

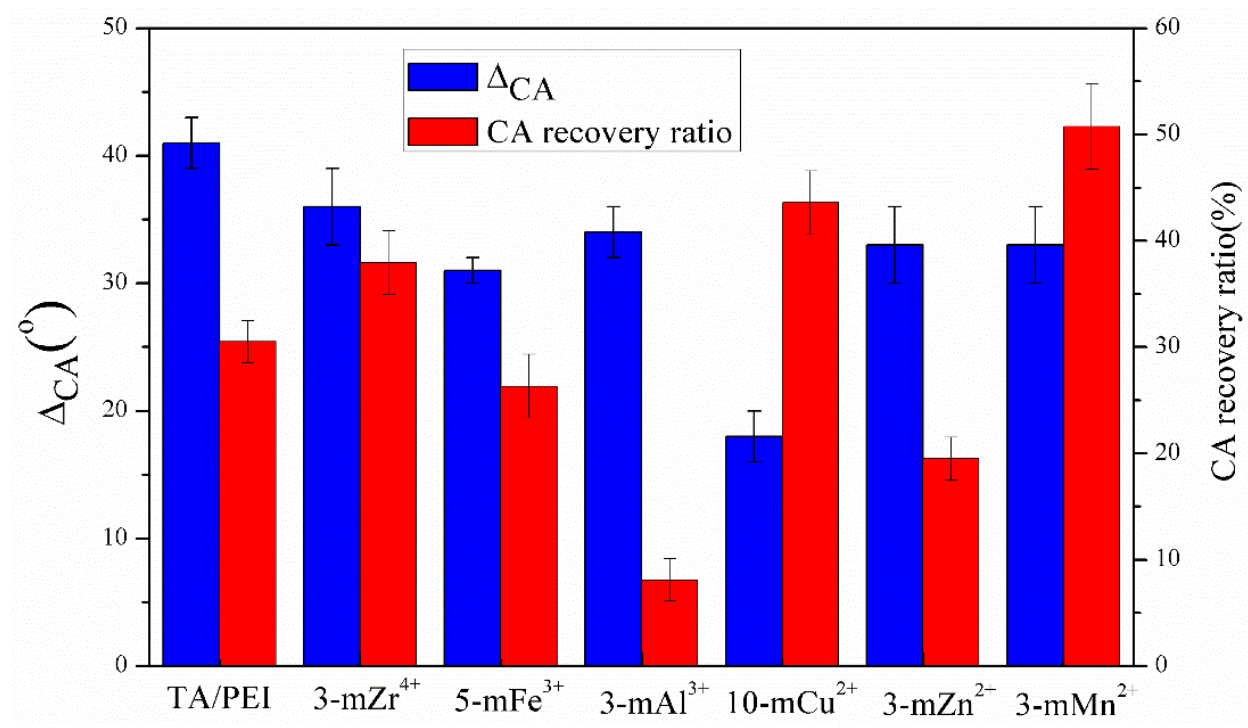

Figure 10. The water contact angle (CA) variation $\left(\Delta_{C A}\right)$ and $C R$ of the TA/PEI/M and TA/PEI modified membranes.

\section{Conclusions}

A super oleophobic PVDF MF membrane was prepared by a simple surface modification method that used TA, PEI, and metal ions. The membrane possessed better stability in pure water when metal ions were applied to coordinate with TA and PEI. The 3- $\mathrm{mAl}^{3+}$ membrane showed the minimum WCA $\left(19^{\circ}\right)$ and maximum OCA $\left(162^{\circ}\right)$, and the $10-\mathrm{mCu}^{2+}$ membrane had the maximum water permeability $\left(13,028 \mathrm{~L} / \mathrm{m}^{2} \cdot \mathrm{h}\right)$. In addition, the resistance of TA/PEI/M modified PVDF MF membranes to toluene was approximately $99 \%$, and the FFR of the modified membranes was higher than $87 \%$, displaying their good anti-fouling performance. This study can provide new insight for the field of surface hydrophilic modification, as inexpensive and eco-friendly modifiers such as tannic acid could see more applications in this field.

Supplementary Materials: The following are available online at http://www.mdpi.com/2073-4360/11/12/1975/s1: Figure S1: FESEM images of the pristine and TA/PEI modified PVDF MF membrane, Figure S2: The influence of modification time of $\mathrm{Zr}^{4+}$ on WCA and OCA of the TA/PEI/M modified PVDF MF membranes. Figure S3: The influence of modification time of $\mathrm{Zr}^{4+}$ on WF of the TA/PEI/M modified PVDF MF membranes, Figure S4: The influence of modification time of $\mathrm{Fe}^{3+}$ on WCA and OCA of the TA/PEI/M modified PVDF MF membranes, Figure S5: The influence of modification time of $\mathrm{Fe}^{3+}$ on WF of the TA/PEI/M modified PVDF MF membranes, Figure S6: The influence of modification time of $\mathrm{Al}^{3+}$ on WCA and OCA of the TA/PEI/M modified PVDF MF membranes, Figure S7: The influence of modification time of $\mathrm{Al}^{3+}$ on WF of the TA/PEI/M modified PVDF MF membranes, Figure S8: The influence of modification time of $\mathrm{Cu}^{2+}$ on WCA and OCA of the TA/PEI/M modified 
PVDF MF membranes, Figure S9: The influence of modification time of $\mathrm{Cu}^{2+}$ on WF of the TA/PEI/M modified PVDF MF membranes, Figure S10: The influence of modification time of $\mathrm{Zn}^{2+}$ on WCA and OCA of the TA/PEI/M modified PVDF MF membranes, Figure S11: The influence of modification time of $\mathrm{Zn}^{2+}$ on WF of the TA/PEI/M modified PVDF MF membranes, Figure S12: The influence of modification time of $\mathrm{Mn}^{2+}$ on WCA and OCA of the TA/PEI/M modified PVDF MF membranes, Figure S13: The influence of modification time of $\mathrm{Mn}^{2+}$ on WF of the TA/PEI/M modified PVDF MF membranes.

Author Contributions: Conceptualization, L.W. and W.C.; methodology, C.L. and Q.L.; resources, L.W.; data curation, C.L and Q.L.; supervision, W.C.; funding acquisition, L.W.; writing, original draft preparation, Q.L and L.W.; writing, review and editing, L.W. and W.C.

Funding: This research was funded by Program of Young Scholar sponsored, grant number 201306955022" and "The Students Innovation and Entrepreneurship Training program was funded by China Scholarship Council".

Acknowledgments: This study was supported by the Program of Young Scholar sponsored by the China Scholarship Council (201306955022) and the Students Innovation and Entrepreneurship Training program (20171049701023).

Conflicts of Interest: The authors declare no conflict of interest.

\section{References}

1. Zhao, X.; Zhang, R.; Liu, Y.; He, M.; Su, Y.; Gao, C.; Jiang, Z. Antifouling membrane surface construction: Chemistry plays a critical role. J. Membr. Sci. 2018, 551, 145-171. [CrossRef]

2. Shannon, M.A.; Bohn, P.W.; Elimelech, M.; Georgiadis, J.G.; Marinas, B.J.; Mayes, A.M. Science and technology for water purification in the coming decades. Nature 2008, 452, 301-310. [CrossRef] [PubMed]

3. Escobar, I.C. Microfiltration and ultrafiltration membrane science and technology. J. Appl. Polym. Sci. 2015, 132, 1. [CrossRef]

4. Yan, L.; Wang, J. Development of new polymer membrane-PVB/PVD blended membrane. Desalination 2011, 281, 455-461. [CrossRef]

5. Lin, X.-C.; An, S. Preparation and properties of PVDF/PVA hollow fiber membranes. Desalination 2010, 250, 530-537.

6. Jiang, J.-H.; Zhu, L.-P.; Zhang, H.-T.; Zhu, B.-K.; Xu, Y.-Y. Improved hydrodynamic permeability and antifouling properties of poly(vinylidene fluoride) membranes using polydopamine nanoparticles as additives. J. Membr. Sci. 2014, 457, 73-81. [CrossRef]

7. Qin, A.-W.; Li, X.; Zhao, X.-Z.; Liu, D.-P.; He, C.-J. Engineering a highly hydrophilic PVDF membrane via binding TiO2 nanoparticles and a PVA layer onto a membrane surface. ACS Appl. Mater. Interfaces 2015, 7, 8427-8436. [CrossRef]

8. Zhao, X.-Z.; Xuan, H.-X.; Chen, Y.-L.; He, C.-J. Preparation and characterization of superior antifouling PVDF membrane with extremely ordered and hydrophilic surface layer. J. Membr. Sci. 2015, 494, 48-56. [CrossRef]

9. Liu, J.; Shen, X.; Zhao, Y.-P.; Chen, L. Acryloyl morpholine-grafted PVDF membrane with improved protein fouling resistance. Ind. Eng. Chem. Res. 2013, 52, 18392-18400. [CrossRef]

10. Yang, X.-X.; Deng, B.; Liu, Z.-Y.; Shi, L.-Q.; Bian, X.-K.; Yu, M. Microfiltration membranes prepare from acryl amide grafted poly(vinylidene fluoride) powder and their $\mathrm{pH}$ sensitive behaviour. J. Membr. Sci. 2010, 362, 298-305. [CrossRef]

11. Shao, L.; Wang, Z.-X.; Zhang, Y.-L.; Jiang, Z.-X.; Liu, Y.-Y. A facile strategy to enhance PVDF ultrafiltration membrane performance via self-polymerized polydopamine followed by hydrolysis of ammonium fluotitanate. J. Membr. Sci. 2014, 461, 10-21. [CrossRef]

12. Xiang, Y.-H.; Liu, F.; Xue, L.-X. Under seawater superoleophobic PVDF membrane inspired by olydopamine for efficient oil/seawater separation. J. Membr. Sci. 2015, 476, 321-329. [CrossRef]

13. Shi, H.; He, Y.; Pan, Y.; Di, H.-H.; Zeng, G.-Y.; Zhang, L.; Zhang, C.-L. A modified mussel-inspired method to fabricate $\mathrm{TiO}_{2}$ decorated superhydrophilic PVDF membrane for oil/water separation. J. Membr. Sci. 2016, 506, 60-70. [CrossRef]

14. Zin, G.; Wu, J.-J.; Rezzadori, K.; Petrus, J.C.C.; DiLuccio, M. Modification of hydrophobic commercial PVDF microfiltration membranes into superhydrophilic membranes by the mussel-inspired method with dopamine and polyethyleneimine. Sep. Purif. Technol. 2019, 212, 641-649. [CrossRef]

15. Kangn, G.D.; Cao, Y.-M. Application and modification of poly(vinylidene fluoride)(PVDF)membranes-A review. J. Membr. Sci. 2014, 63, 145-165. [CrossRef] 
16. Lee, H.; Dellatore, S.M.; Miller, W.M.; Messersmith, P.B. Mussel-Inspired surface chemistry for multifunctional coatings. Science 2007, 318, 426-430. [CrossRef]

17. Silverman, H.G.; Roberto, F.F. Understanding Marine Mussel Adhesion. Mar. Biotechnol. 2007, 9, 661-681. [CrossRef]

18. Ryu, H.J.; Messersmith, P.B.; Lee, H. Polydopamine Surface Chemistry: A Decade of Discovery. ACS Appl. Mater. Interfaces 2018, 10, 7523-7540. [CrossRef]

19. Zhao, C.-Q.; Zhang, G.-Q.; Xu, X.-C.; Yang, F.-L.; Yang, Y.-S. Rapidly self-assembled polydopamine coating membranes with polyhexamethylene guanidine: Formation, characterization and antifouling evaluation. Colloids Surf. A 2017, 512, 41-50. [CrossRef]

20. Guo, X.-Y.; Fan, S.-G.; Hu, Y.-D.; Fu, X.-L.; Shao, H.-Q.; Zhou, Q.-X. A novel membrane biofouling mitigation strategy of D-amino acid supported by polydopamine and halloysite nanotube. J. Membr. Sci. 2019, 579, 131-140. [CrossRef]

21. Li, X.-P.; Shan, H.-T.; Min, C.; Li, B.-A. Mussel-inspired modification of PTFE membranes in a miscible THF-Tris buffer mixture for oil-in-water emulsions separation. J. Membr. Sci. 2018, 555, 237-249. [CrossRef]

22. Jin, J.-B.; Du, X.-L.; Yu, J.; Qin, S.-H.; He, M.; Zhang, K.-Z.; Yang, J.-K. Synthesis of Negatively Charged Polyol-Functional PSF Membranes with Good Hydrophilic and Efficient Boron Removal Properties. Polymers 2019, 11, 780. [CrossRef] [PubMed]

23. Klosterman, L.; Riley, J.K.; Bettinger, C.J. Control of Heterogeneous Nucleation and Growth Kinetics of Dopamine Melanin by Altering Substrate Chemistry. Langmuir 2015, 31, 3451-3458. [CrossRef] [PubMed]

24. Cao, Y.; Zhang, X.; Tao, L.; Li, K.; Xue, Z.; Feng, L.; Wei, Y. Mussel-inspired chemistry and Michael addition reaction for efficient oil/water separation. ACS Appl. Mater. Interfaces. 2013, 54, 4438-4442. [CrossRef]

25. Jiang, Y.; Shi, K.-X.; Tang, H.; Wang, Y.-L. Enhanced wettability and wear resistance on $\mathrm{TiO}_{2} / \mathrm{PDA}$ thin films prepared by sol-gel dip coating. Surf. Coat. Technol. 2019, 375, 334-340. [CrossRef]

26. Zhang, S.-F.; Wu, L.-L.; Deng, F.-R.; Zhao, D.-P.; Zhang, C.; Zhang, C.-C. Hydrophilic modification of PVDF porous membrane via a simple dip-coating method in plant tannin solution. RSC Adv. 2016, 6, 71287-72194. [CrossRef]

27. Virgen-Ortíz, J.J.; Dos Santos, J.C.S.; Berenguer-Murcia, A.; Barbosa, O.; Rodrigues, R.C.; Fernandez-Lafuente, R. Polyethylenimine: A very useful ionic polymer in the design of immobilized enzyme biocatalysts. J. Mater. Chem. B 2017, 36, 7461-7490. [CrossRef]

28. Vicennati, P.; Giuliano, A.; Ortaggi, G.; Masotti, A. Polyethylenimine in Medicinal Chemistry. Curr. Med. Chem. 2008, 15, 2826-2839. [CrossRef]

29. Lim, M.Y.; Choi, Y.S.; Kim, J.; Kim, K.; Shin, H.; Kim, J.J.; Shin, D.M. Cross-linked graphene oxide membrane having high ion selectivity and antibacterial activity prepared using tannic acid functionalized graphene oxide and polyethyleneimine. J. Membr. Sci. 2017, 521, 1-9. [CrossRef]

30. Lv, Y.; Yang, S.-J.; Du, Y.; Yang, H.-C.; Xu, Z.-K. Co-deposition Kinetics of Polydopamine/Polyethyleneimine Coatings: Effects of Solution Composition and Substrate Surface. Langmuir 2018, 34, 13123-13131. [CrossRef]

31. Bacelo, H.A.M.; Santos, S.C.; Botelho, R.C.M.S. Tannin-based biosorbents for environmental applications-A review. Chem. Eng. J. 2016, 303, 575-587. [CrossRef]

32. Guo, J.-L.; Ping, Y.; Ejima, H.; Alt, K.; Meissner, M.; Richardson, J.J.; Yan, Y. Engineering Multifunctional Capsules through the Assembly of Metal-Phenolic Networks. Angew. Chem. Int. Ed. 2014, 53, 1-7.

33. You, F.; Xu, Y.; Yang, X.; Zhang, Y.; Shao, L. Bio-inspired $\mathrm{Ni}^{2+}$-polyphenol hydrophilic network to achieve unconventional high-flux nanofiltration membranes for environmental remediation. Chem. Commun. 2017, 53, 6128-6131. [CrossRef] [PubMed]

34. Zhou, L.; Zhang, G.; Wang, M.; Wang, D.-F.; Cai, D.-Q.; Wu, Z.-Y. Efficient removal of hexavalent chromium from water and soil using magnetic ceramsite coated by functionalized nano carbon spheres. Chem. Eng. J. 2018, 334, 400-409. [CrossRef]

35. Cui, T.-C. The research situation of silane coupling agent. Peak Data Sci. 2017, 4, $214-217$.

36. Ying Kei Lung, C.; Matinlinna, J.P. Aspects of silane coupling agents and surface conditioning in dentistry: An overview. Dent. Mater. 2017, 28, 467-477. [CrossRef] [PubMed]

37. Zhang, Y.Q. Application of silane coupling agents in modified organic anti-corrosive coatings. Guangzhou Chem. Ind. 2017, 45, 16-18.

38. Yang, Y.-F.; Wan, L.; Xu, Z.-K. Surface hydrophilization for polypropylene microporous membranes: A facile interfacial crosslinking approach. J. Membr. Sci. 2009, 326, 372-381. [CrossRef] 
39. Liu, C.; Wu, L.-L.; Zhang, C.-C.; Chen, W.-Y.; Luo, S. Surface hydrophilic modification of PVDF membranes by trace amounts of tannin and polyethyleneimine. Appl. Surf. Sci. 2018, 457, 695-704. [CrossRef]

40. Li, M.; Wu, L.-L.; Zhang, C.-C.; Chen, W.-Y.; Liu, C. Hydrophilic and antifouling modification of PVDF membranes by one-step assembly of tannic acid and polyvinylpyrrolidone. Appl. Surf. Sci. 2019, 483, 967-978. [CrossRef] 